Brit. J. vener. Dis. (1961), 37, 204.

\title{
CLUTTON'S JOINTS*†
}

\section{A BRIEF REVIEW OF THE LITERATURE, AND AN UNUSUAL CASE TREATED WITH INTRA-ARTICULAR HYDROCORTISONE}

\author{
BY \\ P. RODIN \\ The Whitechapel Clinic, The London Hospital
}

Symmetrical synovitis of the knee joint occurring in the course of congenital syphilis, though noted earlier, was first reported in detail by Clutton (1886). From his observations on eleven cases, Clutton was able to delineate the clinical features of the condition with an accuracy which has been fully confirmed by later workers. He described the usually insidious onset of painless effusions into both knee joints, of duration up to one year, with freedom from functional disability and ultimate perfect recovery. Though in all his cases the associated signs were those of congenital syphilis, he noted that the arthritis responded poorly to antisyphilitic therapy. Nine of his eleven cases showed evidence of active interstitial keratitis, and he stressed the similarities in the clinical behaviour of these two conditions.

Clutton considered the condition to be rare, but gave no figures of incidence. Leo (1932) reported twenty cases in a series of 292 congenital syphilitics (7 per cent.). Klauder and Robertson (1934) found 17 per cent. of 363 cases to be affected. Laird (1950), in a survey of 115 patients with late congenital syphilis, found Clutton's joints in four ( 3.5 per cent.). Nabarro (1954), dealing mainly with a paedriatric group, found forty "typical" cases among 465 congenital syphilitics over the age of 2 years $(9$ per cent.).

Klauder and Robertson (1934) found the condition to be more prevalent in females but Nabarro (1954) found the sexes to be affected equally.

The condition usually occurs between the ages of 5 and 20 years, and mainly between 8 and 15 years. The oldest patient in Klauder and Robertson's series was aged 35.

Though the synovitis is commonly reported as being painless, pain occurring in the absence of trauma or infection is a recognized feature in a few

* Short paper read to M.S.S.V.D. on January 29, 1960.

t Received for publication May 25, 1960. cases. The swelling usually begins in one knee joint so that, although it is often bilateral when the patient first seeks advice, the degree of involvement is frequently unequal. Sometimes there is an interval of months or years before the second knee is affected; in one of Clutton's cases 2 years elapsed, and Nabarro reported an interval of 3 years. Involvement of joints other than the knees has been reported. One of Clutton's patients gave a history of ankle swelling preceding the development of synovitis of the knees. Klauder and Robertson (1934) reported involvement of the elbow joint in two of their cases, and the elbows, wrists, fingers, and ankles were affected in cases reported by Jeans and Cooke (1930).

Findings at examination are those of a flaccid effusion. Sometimes synovial thickening may be felt, and tenderness is occasionally elicited. The $X$ ray appearances are those of an increased joint space without evidence of bony changes. Aspirated joint fluid is straw-coloured and slightly turbid, contains occasional leucocytes, and is sterile on culture.

The relationship between Clutton's joints and interstitial keratitis has been explored by several workers. In the series of Klauder and Robertson there was no significant difference between the incidence of Clutton's joints in those with interstitial keratitis and those without, nor was the incidence of interstitial keratitis in cases of Clutton's joints significantly higher than that in the group without joint involvement. Jeans and Cooke (1930) and also Stokes, Beerman, and Ingraham (1944), arrived at a similar conclusion. Oksala (1951) found that sixteen out of 126 patients with interstitial keratitis developed Clutton's joints and that joint involvement preceded or coincided with the development of interstitial keratitis in all except one case. Stokes and others (1944) considered that the development of Clutton's joints could form a valuable premonitory sign of the more serious eye involvement. 
An examination of the case records of the Whitechapel Clinic of the London Hospital showed that between December 31, 1945, and December 31, 1959, 104 patients attended suffering from late congenital syphilis. The average age of this group was 28 years (range 2-78), 54 per cent. being between 11 and 30 years. Clutton's joints were found in five patients (approximately 5 per cent.), whose ages were $8,14,15,20$, and 24 ; two were male and three were female.

The first four of these patients attended with typical bilateral hydrarthroses of the knee joints. In one case there had been an interval of 6 months before the second knee had become affected. In each of these four cases the duration of the joint swelling after the completion of adequate antisyphilitic therapy was between 6 and 9 months. None showed evidence of interstitial keratitis.

The fifth case presented with unusual features and is described in greater detail.

\section{Case Report}

A single woman aged 24 , first attended the Whitechapel Clinic in December, 1953. A history was obtained of the gradual onset 4 months previously of a slightly painful swelling of the left knee occurring without preceding trauma. 3 months after the onset of the joint swelling she developed photophobia and slight pain and redness in the left eye.

Physical Examination.-A small effusion was found in the left knee, together with slight synovial thickening. Movements were full and painless. The right knee and other joints were normal. There was active interstitial keratitis in the left eye. The upper central incisors showed slight barrel-shaped deformity but were not truly Hutchinsonian. There were no other stigmata of congenital syphilis and no other abnormal signs were found in the major systems.

Investigations.-Serological tests for syphilis were as follows:

Wassermann reaction +

Price's precipitation reaction +16

$X$ rays of the knees showed no bony abnormalities. Tests of hearing showed that a mild bilateral perceptive deafness was present. The cerebrospinal fluid was normal. $X$ ray examination showed the shadow of the heart and aorta to be within normal limits.

The patient's mother refused to attend for examination.

Treatment and Course of Illness.-The interstitial keratitis responded rapidly to the local instillation of cortisone drops. 600,000 units procaine penicillin were given intramuscularly each day for 10 days, followed by $0.3 \mathrm{~g}$. metallic bismuth intramuscularly each week for 10 weeks. It was not until 13 months after the completion of this treatment that the left knee returned to normal. The right knee remained normal throughout.

In November, 1959, after an interval of 6 years, the patient stated that she had noticed swelling and slight aching of the right knee for 2 months. Examination revealed a moderate painless effusion in the right knee. The left knee and other joints were normal. There was no active interstitial keratitis. $X$ rays of both knees again showed no bony abnormalities. The Wassermann reaction was still positive, but the Price's precipitation reaction titre had declined to +4 . The erythrocyte sedimentation rate, the white cell count in the blood, and the plasma proteins were within normal limits, and the latex-fixation test was negative. The patient was seen by Dr. R. M. Mason of the Department of Physical Medicine, who confirmed the absence of other causes of hydrarthrosis.

It was decided to try the effects of intra-articular hydrocortisone. $55 \mathrm{ml}$. joint fluid were aspirated and $100 \mathrm{mg}$. hydrocortisone were injected into the knee joint. The aspirated fluid was pale yellow, slightly turbid, and contained 20 leucocytes per $\mathrm{cmm}$., the majority being polymorphonuclear. The fluid was sterile on culture and culture for $\mathbf{M}$. tuberculosis was negative. 3 weeks after aspiration the joint appeared normal at examination, but by the fifth week the fluid had returned. $50 \mathrm{ml}$. joint fluid were then aspirated, but on this occasion no hydrocortisone was injected, and the fluid returned to the knee within 4 days. The patient remained under observation for 2 more weeks during which time there was no change in the condition of the knee. She has not attended since.

\section{Summary}

The literature concerning Clutton's joints is briefly reviewed.

Between 1945 and 1959, 104 patients over the age of 2 years attended the Whitechapel Clinic suffering from congenital syphilis, and Clutton's joints were found in five of them.

The case of a 24-year-old woman, presented in detail, is unusual in that a period of 6 years elapsed before the second knee became involved. It is probable that anti-syphilitic therapy did not influence the course of the disease in the first (left) knee; it did not prevent the second (right) knee from becoming affected. Aspiration of joint fluid followed by the intra-articular injection of hydrocortisone appears to have had a more beneficial effect than aspiration alone.

I should like to record my thanks to Mr. A. J. King, Dr. R. M. Mason and Dr. J. A. H. Hancock for their advice and assistance. 


\section{REFERENCES}

Clutton, H. H. (1886). Lancet, 1, 391.

Jeans, P. C., and Cooke, J. V. (1930). "Prepubescent Syphilis", vol. 17 of "Clinical Pediatrics". Appleton, New York.

Klauder, J. V., and Robertson, H. F. (1934). J. Amer. med. Ass., 103, 236.

Laird, S. M. (1950). Brit. J. vener. Dis., 26, 143.

Leo, F. (1932). Derm. Wschr., 94, 787.

Nabarro, D. (1954). "Congenital Syphilis", p. 227. Arnold, London.

Oksala, A. (1951). Acta derm.-venereol. (Stockh.), 31, Suppl. 24, p. 97.

Stokes, J. H., Beerman, H., and Ingraham, N. R. (1944). "Modern Clinical Syphilology", 3rd ed., p. 1133. Saunders, Philadelphia and London.

\section{Les articulations de Clutton}

\section{Résumé}

L'auteur passe rapidement en revue la littérature sur les articulations de Clutton.

Entre 1945 et 1959, sur 104 syphilitiques de naissance de plus de $\mathbf{2}$ ans traités à la Clinique de Whitechapel, il y eut 5 cas d'articulations de Clutton.

Le cas d'une femme de 24 ans est étudié en détail. Ce cas est remarquable du fait que le genou droit ne fut affecté que 6 ans après le gauche. Il est probable que le traitement anti-syphilitique n'influença pas le cours de la maladie dans le premier genou; il n'empêcha pas l'infection du deuxième genou. L'aspiration de la synovie suivie par l'injection intra-articulaire d'hydrocortisone semble avoir été plus efficace que l'aspiration seule. 